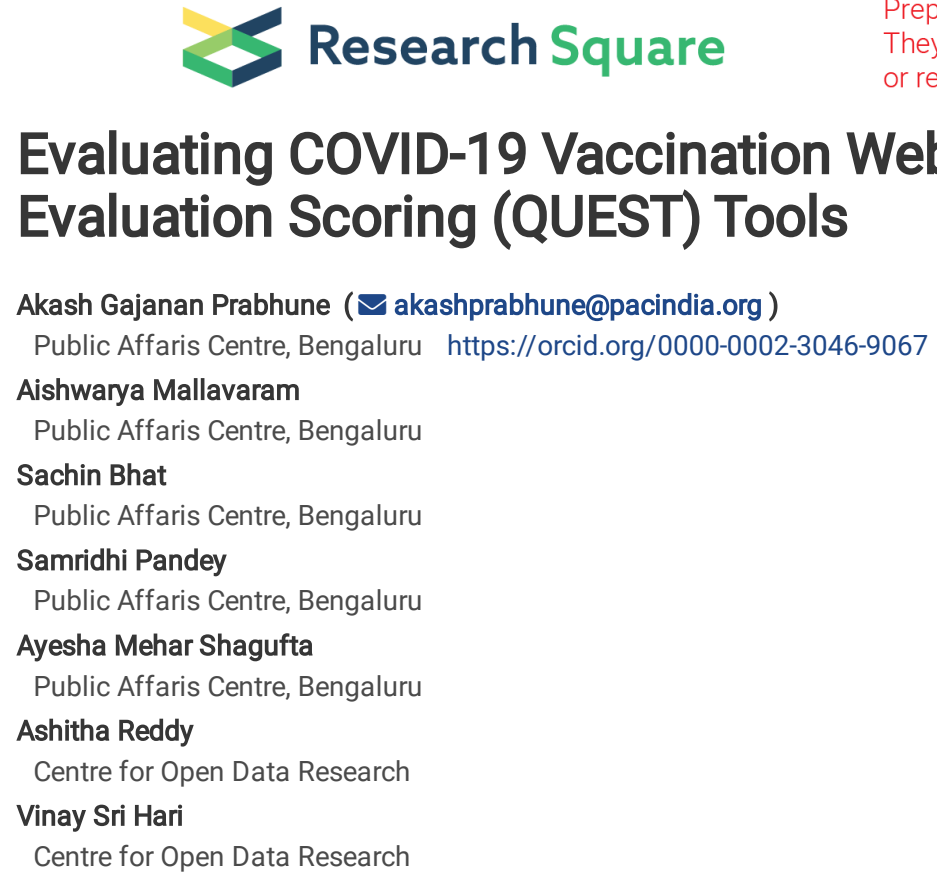

Akash Gajanan Prabhune ( $\square$ akashprabhune@pacindia.org )

Public Affaris Centre, Bengaluru https://orcid.org/0000-0002-3046-9067

\section{Aishwarya Mallavaram}

Public Affaris Centre, Bengaluru

Sachin Bhat

Public Affaris Centre, Bengaluru

Samridhi Pandey

Public Affaris Centre, Bengaluru

Ayesha Mehar Shagufta

Public Affaris Centre, Bengaluru

Ashitha Reddy

Centre for Open Data Research

Vinay Sri Hari

Centre for Open Data Research

\title{
Evaluating COVID-19 Vaccination Website using DISCERN and QUality Evaluation Scoring (QUEST) Tools
}

Research Article

Keywords: COVID-19 Vaccine Registration, Quality of Health Information, Consumer Health Information

Posted Date: June 11th, 2021

DOI: https://doi.org/10.21203/rs.3.rs-604765/v1

License: (c) (i) This work is licensed under a Creative Commons Attribution 4.0 International License. Read Full License 


\section{Abstract}

Background: The objective of this paper was to evaluate the COVID-19 vaccine registration website across UN-recognized member states for their portal quality, reliability, Ease Use and help to the general population in informed decision making.

Methods: 12 UN member states (Countries) were selected based on the inclusion and exclusion criteria mentioned in the methodology section of this paper. PPS technique was used for sampling and selection of 12 countries from 193 UN member states. Post selection of UN member states the study used 2 step evaluation techniques, Step 1 The DISCERN checklist consists of 16 questions in three sections and is aimed to assess the reliability of information and quality of information; Step 2 The QUEST tool consists of 6 items with a subitem, Authorship, Attribution, Conflict of Interest, Complementarity, Currency, Tone. The authors developed a standard set of instructions for evaluating Vaccination Portals to bring uniformity in understanding and context setting.

Results: DISCERN tool overall reliability score on the Likert scale of 0 to 5 was 4 (SD \pm 1.28 ). On Quality of information regarding treatment choices, the average score was 3.4 (SD \pm 1.67 ). The QUEST tool on ease of use, concision, and comprehensiveness demonstrated an average Score of 18.1 (SD \pm 8.3 ) out of 28 .

The vaccine registration portal of the Czech Republic was found to be most informative and was able to provide a piece of scientifically valid information on safety, efficacy, long-term short effects, choice of vaccine with attributable authors details. India, Bangladesh, Nigeria, South Africa scored relatively low to missing critical information on the website. The United Arab Emirates, Republic of South Korea, Indonesia, Australia, and Argentina had minor elements missing.

Conclusions: COVID-19 vaccination portals vary in the quality of information and many were found unable to provide critical information for decision making on getting vaccinated

\section{Key Messages}

\section{Implications for policy-makers}

The Study highlights the pressing need for introducing consumer health informatics approach while designing COVID-19 vaccination portals, the multisectoral involvement is a key to improve the consumer engagement and create conducive environment of mutual trust. The Vaccine hesitancy needs to be tackled in systematic way, and developing a valid, quality and reliable registration portal for COVID-19 vaccination should be considered as first step by policy makers.

\section{Implications for public}

The COVID-19 pandemic has been pandemic of misinformation, and the vaccination campaign has been surrounded by speculations, rumours, this has lead to vaccine hesitancy amongst many. In such situation the Vaccine Registration Portal is the first interface, and should contain valid, reliable information which would enable laymen to undertake and informed decision on vaccination. Our study focus was to evaluate the quality of Vaccine Registration Portals to seek improvement and improve vaccination coverage.

\section{Background}

COVID-19 vaccination has been a key public health issue of 2021 with countries globally investing heavily on providing vaccination coverage to their residents, with over 1.62 billion individuals globally received at least one dose of vaccine and over 383 million individuals globally fully vaccinated (4.9\% of the global population) as on 23rd May $2021^{1}$. The investments and research channelled towards the development and distribution of vaccine are evident with 26 vaccine candidates being available for human use and billions of dollars invested for the development of vaccine candidates ${ }^{2,3}$. A paper published by Wouters et. al ${ }^{3}$ has presented an overview of challenges in production, affordability, allocation, and deployment of COVID-19 vaccines globally. The logistical and administrative challenges related to the identification of individuals in priority groups, digital tools to manage appointments and send reminders for second doses of vaccine were highlighted. To overcome these challenges most countries have mandated pre-registration using specially designed web portals.

The websites designed for registration are the single window of contact between the general population who want to get vaccinated and who are un-decisive for getting vaccinated, thus the vaccine registration portals should be provided to educate individuals on the benefits of getting vaccinate, possible side effects, eligibility information should be mentioned, should be accessible through a range of devices, available in local languages, should include Frequently Asked Questions page, including contact details for more information or chatbot for any queries, able to explain the process of vaccination, direct individuals to nearest vaccination centre.

The objective of this study was to evaluate the COVID19 Vaccine Registration website for Quality of Information, Ease of Navigation and Interaction, and usability across various devices and formats, to enable informed decision making amongst the general population.

\section{Methods}

The objective of this survey was to evaluate the COVID-19 vaccine registration website, thus we used the following inclusion criteria

a. National COVID-19 vaccination portals developed and maintained by the National Health Ministry of any country listed under the United Nations website as the Member States ${ }^{4}$ as of May 2021

b. Nations with running COVID-19 vaccination website as of May 2021 
c. National COVID-19 vaccination portals using English as one of the languages and is visible on Google search within the first two pages of Google search after entering search terms

The exclusion criteria for this study was

a. Regional or Sate owned and operated COVID-19 vaccination portal

b. COVID-19 vaccination website in languages other than English

c. Countries were access to registration website restricted to IP addressed outside country geography

We use a probability proportional to sample size sampling methodology, with an estimated sample of 12 UN-recognized member states based on convivence. In our sampling framework, 193 UN Member states were sorted based on population and stratified into 5 continents of Asia, Australia, Europe, North America, Latin America and Caribbean, and Oceania. Asia continent was further stratified into South East Asia, South Asia, Central Asia, and Middle Eastern Asia, based on population the UN Member sates per stratum were listed in Table 1. The sampling methodology estimated 1 UN Member state for $8.5 \%$ of the global population to be eligible for assessment.

Table 1

Probability Proportional to sample size calculation based on a share in global population

\begin{tabular}{|lll|}
\hline Continent & \% population share of the global population & The number for Member States eligible based on population \\
\hline Africa & $17.2 \%$ & 2 \\
\hline South-East Asia (Asia) & $8.6 \%(59 \%)$ & 1 \\
\hline Eastern and Central Asia (Asia) & $21.95 \%(59 \%)$ & 2 \\
\hline Middle East (Asia) & $3.6 \%(59 \%)$ & 1 \\
\hline South Asia (Asia) & $25 \%(59 \%)$ & 2 \\
\hline Europe & $9.6 \%$ & 1 \\
\hline North America & $4.75 \%$ & 1 \\
\hline Latin America and the Caribbean & $8.3 \%$ & 1 \\
\hline Oceania & $0.54 \%$ & 1 \\
\hline
\end{tabular}

Oceania accounts for $0.54 \%$ of the world population and Eastern and Central Asia accounting for $25 \%$ of the world population necessitate including 12 UN Member states in the sample. For each of the continent and sub-regions we searched for terms "Ministry of Health, Department of Health, Department of Healthcare Services" and "Registration for COVID Vaccine, COVID-19 vaccination portal" with respective country name and selected countries wherein official COVID-19 vaccination link was visible in first two pages of google search engine, for example when we entered search terms "COVID-19 Vaccination Portal for Kuwait + Ministry of Health Kuwait" or "Registration for COVID Vaccine + Department of Health Kuwait" no official links were visible in Page 1 and Page 2 (First 20 search results) of Google Search, thus Kuwait was not selected for Middle East Asia region, whereas as when we entered search terms "COVID-19 Vaccination Portal for Argentina + Ministry of Health Argentina" or "Registration for COVID Vaccine + Department of Health Argentina" the webpage https://www.argentina.gob.ar/coronavirus/vacuna was in the third result on Page 1 of Google search, thus Argentina was included. We sorted UN member states in alphabetically ascending order and search and used search terms against the country name, when Argentina (Alphabetically ascending) the 1rst country in Latin America and the Caribbean was found eligible no other Latin American and Caribbean countries were searched. Based on this methodology following counties COVID-19 vaccination portal were identified for assessment and listed in Table 2. 
Table 2

List of countries selected for assessment of COVID-19 vaccination portal

\begin{tabular}{|c|c|c|}
\hline Country Name & Region & Link for COVID-19 vaccination portal \\
\hline Nigeria & Africa & https://www.health.gov.ng/index.php?option=com_content\&view=article\&layout=edit\&id=268 \\
\hline South Africa & Africa & $\begin{array}{l}\text { https://www.gov.za/covid-19/vaccine?gclid=CjwKCAjw- } \\
\text { qeFBhAsEiwA2G7NI_qCxGI0B02c6TgKinZEApvReev8YdP6MzPLcbKwjpbsa6YPsLwSkhoC6mkQAvD_BwE }\end{array}$ \\
\hline Indonesia & South-East Asia & https://corona.jakarta.go.id/en/vaksinasi \\
\hline Kazakhstan & $\begin{array}{l}\text { Central and } \\
\text { Eastern Asia }\end{array}$ & https://egov.kz/cms/en/online-services/for_citizen/Zapis-na-vakcinaciyu \\
\hline $\begin{array}{l}\text { Republic of } \\
\text { South Korea }\end{array}$ & $\begin{array}{l}\text { Central and } \\
\text { Eastern Asia }\end{array}$ & https://ncv.kdca.go.kr/ \\
\hline $\begin{array}{l}\text { United Arab } \\
\text { Emirates }\end{array}$ & Middle East Asia & https://www.mohap.gov.ae/en/AwarenessCenter/Pages/Covid-19-Vaccination-Booking-Steps.aspx \\
\hline Bangladesh & South Asia & https://surokkha.gov.bd/ \\
\hline India & South Asia & https://www.cowin.gov.in/home \\
\hline Czech Republic & Europe & https://registrace.mzcr.cz/ \\
\hline Canada & North America & $\begin{array}{l}\text { https://www.canada.ca/en/public-health/services/diseases/coronavirus-disease-covid-19/vaccines/how- } \\
\text { vaccinated.html\#a1 }\end{array}$ \\
\hline Argentina & $\begin{array}{l}\text { Latin America and } \\
\text { Caribbean }\end{array}$ & https://www.argentina.gob.ar/coronavirus/vacuna \\
\hline Australia & Oceania & https://www.health.gov.au/resources/apps-and-tools/covid-19-vaccine-eligibility-checker \\
\hline
\end{tabular}

Post selection of UN member states (Countries) all the vaccination portals were accessed in series, we used two instruments to evaluate the selected portals, as each of these instruments evaluates different aspects of portal quality

1. The DISCERN checklist ${ }^{5}$ consists of 16 questions in three sections. First Section assesses the reliability of the websites using 8 questions. Second Section assesses the quality of information on treatment choices with 7 questions. The third Section with the Last question rates the overall rating of the publication based on the answers to all the previous 15 questions. The DISCERN rating scale for each question is 1 to 5 , where $1=$ definite NO, $3=$ partially and $5=$ definite Yes.

2. The QUEST tool ${ }^{6}$ consists of 6 items with a subitem, Authorship, Attribution, Conflict of Interest, Complementarity, Currency, Tone, the Attribution has Subitem of "type of study". Each item is weighted on two factors: (i) how critical the item is to the overall quality of the article, established by a preliminary analysis of a sample of websites, and (ii) consideration of the criterion's ethical implications. Weight for Authorship is $1 \mathrm{X}$ the score, Attribution is $3 \mathrm{X}$ the score, Type of Study is $1 \mathrm{X}$ the score, Conflict of Interest is $3 \mathrm{X}$ the score, Complementarity is $1 \mathrm{X}$ the score, Currency is $1 \mathrm{X}$ the score, and for Tone is $3 X$ the score. The QUEST rating scale for each item is 2 to 0 , where $2=$ Highest score, $1=$ Median score and $0=$ lowest score

For understanding usability across various devices and formats we used the Google test for mobile-friendliness.

The setting of Context to evaluation

The study objective was to evaluate the Vaccination portals for the information provided by governments across UN Member states from a perspective of the general population and how the COVID-19 vaccination portals are equipped to help in informed decision making.

The DISCERN tool and QUEST tool were used for assessment as the DISCERN tool covers reliability, and quality of information about treatment choices, while QUEST tool covers ease of use, concision and comprehensiveness

Thus, the authors had series of discussion and developed a standardised guideline to interpreting the questions and set in context-specific to the study. The same is presented in Table 3. 
Table 3

Guideline for authors to an undertaken evaluation in the context of the study

Question with an explanation provided

DISCERN tool

Section 1 - Reliability of the Publication

\section{Are the aims clear?}

Hint: Look for a clear indication at the beginning of the publication of * what it is about * what it is meant to cover (and what topics are meant to be excluded) * who might find it useful

\section{Does it achieve its aims?}

Hint: Consider whether the publication provides the information it aimed to as outlined in Question 1

3. Is it relevant?

Hint: Consider whether * the publication addresses the questions that readers might ask * recommendations and suggestions concerning treatment choices are realistic or appropriate

4. Is it clear what sources of information were used to compile the publication (other than the author or producer)?

Hint: * Check whether the main claims or statements made about treatment choices are accompanied by a reference to the sources used as evidence (e.g. a research study or expert opinion) * Look for a means of checking the sources used such as a bibliography/reference list or the addresses of the experts or organisations quoted

5) Is it clear when the information used or reported in the publication was produced?

Hint: Look for * dates of the main sources of information used to compile the publication * date of any revisions of the publication (but not dates of reprinting) * date of publication (copyright date) Rating note: The hints are placed in order of importance- to score a full ' 5 ' the dates relating to the first hint should be found

6) Is it balanced and unbiased?

Hint: Look for * a clear indication of whether the publication is written from a personal or objective point of view * evidence that a range of sources of information was used to compile the publication (e g. More than one research study or expert)* evidence of an external assessment of the publication. Be wary if * the publication focuses on the advantages or disadvantages of one particular treatment choice without reference to other possible choices * the publication relies primarily on evidence from single cases (which may not be typical of people with this condition or responses to a particular treatment) *the information is presented in a sensational, emotive or alarmist way

7. Does it provide details of additional sources of support and information?

Hint: Look for suggestions for further reading or details of other organisations providing advice and information about the condition and treatment choices
Context set for study

Since COVID-19 vaccination is handled by Government, the context here should be verified that the website we are referring to is the official website of the Ministry of Health/ Department of Health of the country.

In some cases, me too websites have popped up misguiding people

For any COVID-19 vaccination portal, the focus should be on

a) Providing information about the vaccination programme

b) Explain the process of getting vaccinated

c) Provide a link for registration

These key details should be seen on the Homepage

In case the details are present on the home screen does it display key information intuitive enough to explore details

From the perspective of laymen, look for the information

- Do the websites states if vaccination is compulsory by law of the land?

- Does the website say clearly about the advantage of getting vaccinated?

- Does it mention any adverse effects of vaccination?

- Is there any mention about the compensation or directs to appropriate authority in case of an adverse event?

Look for the source mentioned under the above-mentioned topics,

Like studies conducted within the country by the regulatory body or studies published by manufacturer cited

Look at the mention of revision of the information.

Specifically, when the gap between the first and second dose was increased for some vaccines, is the document supporting changes cited and date the change implemented

Here our focus should be on looking balance between the explanation given on the safety profile and the benefits of the vaccine.

Are benefits overtly stated while details about safety are underwritten?

Has the website provided a link to read in detail about the studies that were used as evidence to approve the use of the vaccine in-country, look for CTRI registration details 


\section{Question with an explanation provided}

8. Does it refer to areas of uncertainty?

Hint: * Look for discussion of the gaps in knowledge or differences in expert opinion concerning treatment choices * Be wary if the publication implies that a treatment choice affects everyone in the same way (e.g. $100 \%$ success rate with a particular treatment)

Section 2 How Good Is the Quality of Information on Treatment Choices?

9. Does it describe how each treatment works?

Hint: Look for a description of how a treatment acts on the body to achieve its effect

10. Does it describe the benefits of each treatment?

Hint: Benefits can include controlling or getting rid of symptoms, preventing recurrence of the condition and eliminating the condition -both short-term and long-term

11. Does it describe the risks of each treatment?

Hint: Risks can include side effects, complications and adverse reactions to treatment - both short-term and long-term

\section{Context set for study}

Look for the information that describes the use of vaccines to control the pandemic, look if the portal is making statements like

"Vaccines will provide you complete protection against COVID-19" or "You don't need to use the mask after vaccination" such statements should be a sign of poor quality

Focus on information provided regarding various vaccines supplied in the country

Look for information on how vaccine helps to build your immunity against COVID-19, is the information given in simple language, will the layperson understand the information easily, are any simplified examples given to make it relatable

Look at the information in the FAQ section on

a) Will vaccine provide lifetime immunity against COVID-19

b) What are the chances of getting infected after 1 st dose of vaccine, 2 nd dose of vaccine

c) How many days will it take to develop immunity after getting vaccinated

Look for the information on common side effects of the vaccine, data on side effects on people with comorbidities, people on certain medications and systemic complications

Information on severe adverse events, any data on long term effect if available

Look for any information given on

a) Conditions, population, age group wherein sufficient data on vaccine efficacy and safety is not available thus these populations can delay vaccination

b) Is any specific condition, population wherein vaccination is not recommended permanently

Here look for the difference between getting vaccinated and not vaccinated, are any effects mentioned for the people who are getting vaccinated, like the risk of developing serious COVID-19 complication in vaccinated people is much lesser than people who are not vaccinated

As the question here is between getting vaccinate and not getting vaccinated, the focus while answering this question should be on "between various vaccines available is their clear information available as to which vaccine is has shown better efficiency, better safety profile under what circumstances *suggestions of alternatives to consider or investigate further (including
choices not fully described in the publication) before deciding whether to select or reject a particular treatment choice

15. Does it provide support for shared decision-making?

Hint: Look for suggestions of things to discuss with family, friends, doctors or other health professionals concerning treatment choices

Section 3 Overall Rating of The Publication

16. Based on the answers to all of the above questions, rate the overall quality of the publication as a source of information about treatment choices

QUEST Tool
Look in the section "things to know before getting vaccinated", "do's and don'ts before vaccination" which mentions consulting your General Practitioner if you are suffering from specific conditions or if you have been treated for COVID-19 earlier

Take a comprehensive of all the information you read through the portal and think from laymen perspective; How much impact the information available on the portal is making to get vaccinated or is it adding to more confusion, or discouraging you from getting vaccinated 


\begin{tabular}{|c|c|}
\hline Question with an explanation provided & Context set for study \\
\hline Authorship & $\begin{array}{l}\text { As the website is owned by Department of } \\
\text { Health, please look at the mention of } \\
\text { committee, teams, departments which have } \\
\text { written the content for the webpage }\end{array}$ \\
\hline \multirow[t]{2}{*}{ Attribution } & $\begin{array}{l}\text { Is the appropriate source of information } \\
\text { cited, for information written, are hyperlinks } \\
\text { available for further reading? }\end{array}$ \\
\hline & $\begin{array}{l}\text { Claims on safety and efficiency are } \\
\text { supported with appropriate citations of } \\
\text { research studies }\end{array}$ \\
\hline For all articles scoring 2 or 3 on Attribution- Type of Study & $\begin{array}{l}\text { Look at the study designs for cited studies, } \\
\text { Meta-analysis carries the highest value, } \\
\text { followed by RCT and observational studies }\end{array}$ \\
\hline Currency & $\begin{array}{l}\text { Look for the date when statistics on } \\
\text { vaccination coverage were updated, look for } \\
\text { the date given on the last information } \\
\text { update }\end{array}$ \\
\hline Complementarity & $\begin{array}{l}\text { Look at details to ask questions to service } \\
\text { providers, like Chatbot, social media handles } \\
\text { to ask questions, also check if the answers } \\
\text { are sound and scientific }\end{array}$ \\
\hline \multirow[t]{3}{*}{ Tone } & $\begin{array}{l}\text { Look at the overall tone of the website, if the } \\
\text { information overly assertive on benefits of } \\
\text { the vaccine, clearly highlighted on benefits } \\
\text { and has no mention about adverse events, } \\
\text { possible risks }\end{array}$ \\
\hline & Or \\
\hline & Has emphasised on risk and adverse events \\
\hline
\end{tabular}

\section{Results}

The vaccination registration portals of 12 countries were systematically assessed by authors and based on the assessment scoring using DISCERN and QUEST tool was undertaken in series. Author AP assessed the Republic of South Korea, VS assessed Bangladesh, AM assessed Argentina and Canada, AS the assessed Republic of South Africa and Nigeria, SB assessed Indonesia, Kazakhstan and the Czech Republic, SP assessed Australia and India, AR assessed the United Arab Emirates. The standardisation in assessment was brought in by Guideline for authors (Table 3), by developing a consensus document to refer to in case of confusion.

In the results section, we are present the average score across all the member state for all the questions in DISCERN tool along with descriptive analysis on the reason for some member states scoring high while some scoring less. For the QUEST tool for all the seven areas the scores are presented in the table and descriptive analysis is presented

From our analysis, the Republic of South Korea, Indonesia and the Czech Republic were the three countries that scored the highest overall score of 5 in DISCERN tool, Czech Republic and the United Arab Emirates scored a maximum score of 28 on the QUEST tool. Overall across both the tools Czech Republic's website for COVID-19 registration was found to be having the highest Quality of Information, Ease of Navigation and Interaction and was found to be mobilefriendly.

Vaccination Registration portals of all the 12-member state assessed were found to be mobile-friendly.

\section{DISCERN Tool analysis}

For question 1 (Are the aims clear?); all member states assessed except Bangladesh were rated a score of 5 on the Likert scale. The mean score across all the member states was 4.8 (SD \pm 0.87 ) Bangladesh scored 2 because the website didn't mention statistics on vaccination drive in the country "Providing information about the vaccination programme", the homepage did provide the link for registration and explained the process of getting vaccinated.

For question 2 (Does it achieve its aims?); the average score across all the member states was 4.6 (SD \pm 0.67$)$. Republic of South Korea, Argentina, Canada, Nigeria, South Africa, Indonesia, Kazakhstan, and the Czech Republic scored 5 on Likert scale of 0 to 5 , Australia, India, and United Arab Emirates score 4 on Liker scale of 0 to 5 , Bangladesh scored 3 as details on home screen were limited and not intuitive enough to explore details.

For question 3 (Is it relevant?); the average score across all the member states was 4.5 (SD \pm 0.67$)$. Republic of South Korea, Argentina, Canada, Indonesia, Kazakhstan, Czech Republic, United Arab Emirates scored 5 on a Likert scale of 0 to 5, Nigeria, South Africa, Australia and Bangladesh scored 4 on the same Likert Scale. India scored 3 on relevance due to lack of information on, the advantage of getting vaccinated, is it compulsory to get vaccinated, adverse events on vaccination were not given, only details to contact in case of adverse events was given 
For question 4 (Is it clear what sources of information were used to compile the publication?); the average score across all the member states was 3.8 (SD \pm 1.42). Republic of South Korea, Argentina, Canada, Indonesia, Czech Republic scored 5 on a Likert scale of 0 to 5 , South Africa, Australia, United Arab Emirates scored 4 on the same Likert Scale. Nigeria scored 3, India scored 2, Bangladesh scored 1 as the source of information was not quoted, in the case of Bangladesh and India all the information was without a single cited source, Nigeria had cited Nigeria Centre for Disease Control in some instances.

For question 5 (Is it clear when the information used or reported in the publication was produced?); the average score across all the member states was 3.8 $(\mathrm{SD} \pm 1.71)$. The scores on the Likert scale were similar to question 4

For question 6 (Is it balanced and unbiased?); the average score across all the member states was 3.7 (SD \pm 1.61 ). Argentina, Canada, Australia, Indonesia, Czech Republic, United Arab Emirates score 5 on a Likert scale of 0 to 5 . Indian and Bangladesh scored 1 and Kazakhstan score 2 because no information was given safety profile, the efficacy of various vaccines available in the country, also no mention about common side effects were given on the website. Nigeria scored 3 , with a little mention of adverse effects.

For question 7 (Does it provide details of additional sources of support and information?); the average score across all the member states was 3.6 (SD \pm 1.68 ). Argentina, Canada, Australia, Indonesia, Czech Republic, United Arab Emirates scored 5 on Likert scale of 0 to 5, and the Republic of South Korea scored 4, as the links were provided to studies conducted by the vaccine manufacturer or clinical trial conducted within the country to comply with local approval procedures. South Africa and India scored 1 as no links for additional resources were mentioned across the website while Bangladesh and Kazakhstan scored 2 as they referred to helpline number for further information. While Nigeria Score 3 as it referred to infographics for further reading.

For question 8 (Does it refer to areas of uncertainty?); the average score across all the member states was 3.2 (SD \pm 1.64 ). Republic of South Korea, Canada, Indonesia and the Czech Republic scored 5 on the Likert Scale of 0 to 5 as the information referred to the uncertainty of getting infected even after complete vaccination, need to follow social distancing and other preventive measures. The United Arab Emirates scored 4 and Australia scored 3 as they emphasised the need to follow social.

The average score for Sect. 1 (Question 1 to 8 ) focussed on reliability, was 4 (SD \pm 1.28 ). Section 2 (Question 9 to 15 ) focussed on the quality of information regarding treatment choices, the average score for Sect. 2 was 3.4 (SD \pm 1.67 )

For question 9 (Does it describe how each treatment works?); the average score across all the member states was 3.3 (SD \pm 1.71 ). Argentina, Canada, Indonesia, Czech Republic scored 5 on a Likert scale of 0 to 5 as the information on how vaccines help in building immunity, how much per cent immunity against COVID-19 is demonstrated through studies, and variation in immunity between first and second dose was clearly explained. Republic of South Korea, Australia, United Arab Emirates scored 4 on the same Likert scale as the information on variation in immunity between 1 st and 2 nd dose was not reported. Kazakhstan, Bangladesh scored 2 and India, Nigeria and South Africa scored 1 as no information on pathways of immunity build-up, percentage of immunity achieved after first and second wave was provided.

For question 10 (Does it describe the benefits of each treatment?); the average score across all the member states was 4.0 (SD \pm 1.54 ). Republic of South Korea, Argentina, Canada, Nigeria, South Africa, Indonesia, Czech Republic, and the United Arab Emirates scored 5 on the Likert Scale of 0 to 5 . These countries have mentioned the benefit of getting vaccinated, for healthy individuals, special populations, Individuals previously diagnosed and treated for COVID-19. Australia scored 3, Bangladesh and Kazakhstan scored 2, as some kind of information is provided on the benefit of getting vaccinated. India scores 1 as no information was given on the benefit of receiving a vaccine against not getting it.

For question 11 (Does it describe the risks of each treatment?); the average score across all the member states was 3.7 (SD \pm 1.56 ). Republic of South Korea, Argentina, Canada, Indonesia, Czech Republic, United Arab Emirates, scored 5 on Likert Scale of 0 to 5 . These countries have included a section on common adverse events, severe adverse events if any, contact details in case of severe adverse events, the scheme for compensation in cases of severe adverse events, they also mentioned the risk associated with refusing to get vaccinated. Australia scored 4 as the compensation plan was not mentioned in case of severe adverse events. Nigeria scores 3 while Bangladesh and Kazakhstan scored 2 on the same Likert scale as information only on common adverse events was given. India score 1 as no information on the risk of getting vaccinated was provided.

For question 12 (Does it describe what would happen if no treatment is used?); the average score across all the member states was 3.1 (SD \pm 1.73 ). Argentina, Nigeria, Indonesia, Czech Republic, scored 5 on the Likert Scale of 0 to 5 , as they mentioned if the vaccine is compulsory or voluntary. Australia and the United Arab Emirates scored 4 as the information required navigation through the website to locate. Bangladesh, Kazakhstan, South Africa Scored 2, while the Republic of South Korea, Canada, India score 1 as no information was available if the vaccine was refused.

For question 13 (Does it describe how the treatment choices affect the overall quality of life?); the average score across all the member states was 2.8 (SD \pm 1.80). Canada, Indonesia, Czech Republic, United Arab Emirates, scored 5 on the Likert Scale of 0 to 5 , as they have mentioned the effect on the quality of life in the short term, medium-term and long term. The Republic of South Korea scored 4 on the same scale as the only short-term impact on quality of life was mentioned. Australia, Bangladesh, Kazakhstan scored 2 while India, South Africa, Nigeria, Argentina scored 1 as little to no information was found regarding the impact on quality of life.

For question 14 (Is it clear that there may be more than one possible treatment choice?); the average score across all the member states was 4 (SD \pm 1.65 ). Argentina, Canada, South Africa, Australia, Indonesia, Czech Republic and the United Arab Emirates scored 5 on a Likert scale of 0 to 5 as they detailed out various vaccines available, safety profile and efficiency profile of each vaccine, allowed individuals to select specific manufacturers vaccine. The Republic of South Korea scored 4 on the same Likert scale as the information was available, but didn't allow individuals to choose the vaccine of their choice. India scored 4 as it allowed to choose between allowed vaccines by the information on safety and efficacy profile of various vaccines was not given. Kazakhstan scored 2 
as it listed out various vaccines available. Bangladesh and Nigeria didn't provide any information on the type of vaccines available nor allowed to choose between manufacturers

For question 15 (Does it provide support for shared decision-making?); the average score across all the member states was 3.4 (SD \pm 1.51 ). Canada, Indonesia, Czech Republic and the United Arab Emirates scored 5 on a Likert Scale of 0 to 5 as they provided toll-free landline number to connect with GP on for any further questions, listed out do's and don'ts, asked individuals to consult to a general practitioner for more information. Republic of South Korea, Australia scored 4 on the same Likert scale, Nigeria, India and Bangladesh scored 3. Kazakhstan scores 2 while South Africa and Argentina scored 1 as lesser information was provided to connect for further queries.

Overall on DISCERN tool, the Czech Republic scored a perfect 5 across all the 15 questions, the average score across all the member states for DISCERN tool was 3.6 (SD \pm 1.63 ). The UN Member state-specific scores are added in the supplementary material.

\section{QUEST Tool Analysis}

The maximum score on the QUEST tool was 28 across all 7 parameters. The Czech Republic and the United Arab Emirates scored $28(100 \%)$, followed by Indonesia, Kazakhstan and the Republic of South Korea. South Africa scored the lowest score followed by India. The detailed score is presented in Table 4 across all the 12-member states

Table 4

QUEST tool scores for all the 12-member states

\begin{tabular}{|c|c|c|c|c|c|c|c|c|}
\hline Name of the Member State & Score Authorship & $\begin{array}{l}\text { Score } \\
\text { Attribution }\end{array}$ & $\begin{array}{l}\text { Score } \\
\text { Type of Study }\end{array}$ & $\begin{array}{l}\text { Score } \\
\text { Conflict }\end{array}$ & $\begin{array}{l}\text { Score } \\
\text { Currency }\end{array}$ & $\begin{array}{l}\text { Score } \\
\text { Complementarity }\end{array}$ & Score Tone & Score Total \\
\hline Republic of South Korea & 1 & 6 & 2 & 6 & 2 & 1 & 6 & 24 \\
\hline Argentina & 1 & 3 & 2 & 0 & 0 & 1 & 6 & 13 \\
\hline Canada & 1 & 3 & 2 & 6 & 0 & 0 & 3 & 15 \\
\hline Nigeria & 1 & 0 & 0 & 6 & 0 & 1 & 6 & 14 \\
\hline South Africa & 1 & 0 & 0 & 0 & 2 & 0 & 0 & 3 \\
\hline Australia & 2 & 3 & 2 & 6 & 2 & 0 & 3 & 18 \\
\hline India & 2 & 0 & 0 & 0 & 2 & 0 & 3 & 7 \\
\hline Indonesia & 2 & 9 & 1 & 6 & 2 & 1 & 6 & 27 \\
\hline Bangladesh & 2 & 0 & 1 & 6 & 0 & 0 & 6 & 15 \\
\hline Kazakhstan & 2 & 9 & 1 & 6 & 0 & 1 & 6 & 25 \\
\hline Czech Republic & 2 & 9 & 2 & 6 & 2 & 1 & 6 & 28 \\
\hline United Arab Emirates & 2 & 9 & 2 & 6 & 2 & 1 & 6 & 28 \\
\hline
\end{tabular}

QUEST tool was used to understand ease of use, concision and comprehensiveness, the Vaccination website of the Czech Republic and the United Arab Emirates scored the maximum possible points. The Czech Republic also scored 5 on a Likert scale of 0 to 5 on DISCERN tool.

\section{Discussion}

We hypothesised that the Vaccine Registration portals act as a primary source of valid information to the general population planning to get vaccinated, thus the registration portals should be developed with consumer health informatics principles enabling individuals to make an informed decision. While evaluating the registration portals of $12 \mathrm{UN}$ Member states, it was seen that overall efforts were made to include relevant information on the process of registration, cost of the vaccine, where to get vaccinated, but the information on the safety, the efficacy of the vaccine, is vaccination compulsory, choice of the vaccine was not readily available. The vaccine registration portal of the Czech Republic was found to be most informative and was able to provide a piece of scientifically valid information on safety, efficacy, long term short effects, choice of vaccine with attributable authors details. India, Bangladesh, Nigeria, South Africa scored relatively low to missing critical information on the website. The United Arab Emirates, Republic of South Korea, Indonesia, Australia and Argentina were having minor elements missing.

We subjected the Vaccination portals of all the 12 member states to the Google ${ }^{\text {TM }}$ Page Speed Insights test ${ }^{7}$ wherein all the portals were found compatible with Smartphones and Laptops, however, the loading speeds were much better on Laptops and Personal Computers as compared to smartphones

From our study, we were able to develop a list of key areas, to be incorporated in any national COVID-19 vaccination portal to enable individuals to make an informed decision on getting vaccinated.

Reliability of the information - The vaccination portal should act as a gold standard for getting reliable and updated information on the COVID-19 vaccination, the reliability is linked with credentials of people involved in reviewing and synthesizing the information, the name and affiliations of the authors should be given with the date of last information was an update. The information should include global, and regionally-specific data abstracted from the studies conducted for approval and post-approval of the vaccine. 
Quality of the information on treatment choices - The vaccination portal should address the questions on the efficacy of vaccines available, safety profile, the effect of the vaccine on quality of life, voluntarily and scope of differing from getting vaccinated, information of current availability of vaccines to specific groups and populations.

Ease of use - The home screen of the vaccination portal should be designed be to intuitive to enable individuals to browse the content throughout the website, the font size, font style, animations and theme should be legible on small screens (less than 6 inches diagonal size) and large screens (more than 10 inches diagonal size). Animations should be minimum, information should be available in multiple languages (English and regional language at least), availability of specially-abled friendly tools.

Concision and Comprehensiveness - The portal should include concise information specific to COVID-19 vaccination avoiding regional, non-specific messages on the portal.

We ran a correlation analysis to explore the relationship between COVID-19 vaccination rate and the DISECRN and QUEST scores. The data on rate of vaccination form Mathieu et $\mathrm{a}^{8}$. The rate of individuals administered at least one dose of vaccine per million population as on 27 th May 2021 was abstracted and scatter plots were plotted against DISCERN Score and QUEST Score.

The Pearson Correlation Co-efficient value for relation between vaccination rate per million and DISCERN score was 0.61 ( $P$ value 0.05 ), Fig. 1 presents the scatter plot.

The Pearson Correlation Co-efficient value for relation between vaccination rate per million and QUEST score was 0.51 ( $P$ value 0.10 ), Fig. 2 presents the scatter plot.

The Scatter plot added a limited value as the rate of vaccination is influenced by variety of factors other than quality of information.

The current study to our knowledge is the first of a kind to assess the quality of the COVID-19 vaccination website from a consumer health perspective and evaluate the information for reliability, quality on treatment choices, ease of use, concision and comprehensiveness. The study has its limitations as the information on the websites is updated due to the dynamism of COVID-19 treatment and vaccination guidelines, the study might not be replicable with similar results.

\section{Conclusions}

Our study concluded that on DISCERN tool overall reliability score on the Likert scale of 0 to 5 was 4 (SD \pm 1.28 ). On Quality of information regarding treatment choices, the average score was 3.4 (SD \pm 1.67 ). The QUEST tool on ease of use, concision and comprehensiveness demonstrated an average score of 18.1 (SD \pm 8.3). The vaccination portal of the Czech Republic scored the maximum score across DISCERN and QUEST tool. UN Member states of India, Bangladesh, Nigeria, South Africa scoring lower than their counterparts were due to a lack of clear information on treatment choices, limited information on the safety and efficacy of vaccines.

The low score indicates lack of Consumer Health Informatics hindsight, while developing the portal. However, as these websites are the only portals for registration, and effective and strategic placement of critical information, which would enable general population to develop trust on the vaccination drive and clear their doubts is a key to deter vaccine hesitancy and improve vaccination rate. Countries like India, Bangladesh, South Africa, Nigeria have huge population to vaccinate and a reliable and quality vaccine registration portal should be the first priority of the administration.

\section{References}

1. global covid vaccine tracker map - Google Search. Accessed May 23, 2021. https://www.google.com/search? q=global+covid+vaccine+tracker+map\&safe=strict\&rlz=1C1YQLS_enIN888IN888\&biw=1366\&bih=600\&sxsrf=ALeKk01HX36gBU4_4kUsie-

2. Li Y, Tenchov R, Smoot J, Liu C, Watkins S, Zhou Q. A Comprehensive Review of the Global Efforts on COVID-19 Vaccine Development. ACS Cent Sci. 2021;7(4):512-533. doi:10.1021/acscentsci.1c00120

3. Wouters OJ, Shadlen KC, Salcher-Konrad M, et al. Challenges in ensuring global access to COVID-19 vaccines: production, affordability, allocation, and deployment. The Lancet. 2021;397(10278):1023-1034. doi:10.1016/S0140-6736(21)00306-8

4. Nations U. Member States. United Nations. Accessed May 23, 2021. https://www.un.org/en/about-us/member-states

5. Charnock D, Shepperd S, Needham G, Gann R. DISCERN: an instrument for judging the quality of written consumer health information on treatment choices. J Epidemiol Community Health. 1999;53(2):105-111.

6. Robillard JM, Jun JH, Lai J-A, Feng TL. The QUEST for quality online health information: validation of a short quantitative tool. BMC Med Inform Decis Mak. 2018;18. doi:10.1186/s12911-018-0668-9

7. About PageSpeed Insights. Google Developers. Accessed June 3, 2021. https://developers.google.com/speed/docs/insights/v5/about

8. A global database of COVID-19 vaccinations | Nature Human Behaviour. Accessed June 8, 2021. https://www.nature.com/articles/s41562-021-01122-8

\section{Appendix}

Appendix 1 - DISCENR tool score 


\begin{tabular}{|c|c|c|c|c|c|c|c|c|c|c|c|c|}
\hline $\begin{array}{l}\text { Name of the } \\
\text { country }\end{array}$ & $\begin{array}{l}\text { Republic } \\
\text { of } \\
\text { South } \\
\text { Korea }\end{array}$ & Argentina & Canada & Nigeria & $\begin{array}{l}\text { South } \\
\text { Africa }\end{array}$ & Australia & India & Indonesia & Bangladesh & Kazakhstan & $\begin{array}{l}\text { Czech } \\
\text { Republic }\end{array}$ & $\begin{array}{l}\text { United } \\
\text { Arab } \\
\text { Emiratı }\end{array}$ \\
\hline $\begin{array}{l}\text { 1. Are the } \\
\text { aims clear? }\end{array}$ & 5 & 5 & 5 & 5 & 5 & 5 & 5 & 5 & 2 & 5 & 5 & 5 \\
\hline $\begin{array}{l}\text { 2. Does it } \\
\text { achieve its } \\
\text { aims? }\end{array}$ & 5 & 5 & 5 & 5 & 5 & 4 & 4 & 5 & 3 & 5 & 5 & 4 \\
\hline $\begin{array}{l}\text { 3. Is it } \\
\text { relevant? }\end{array}$ & 5 & 5 & 5 & 4 & 4 & 4 & 3 & 5 & 4 & 5 & 5 & 5 \\
\hline $\begin{array}{l}\text { 4. Is it clear } \\
\text { what } \\
\text { sources of } \\
\text { information } \\
\text { were used to } \\
\text { compile the } \\
\text { publication } \\
\text { (other than } \\
\text { the author or } \\
\text { producer)? }\end{array}$ & 5 & 5 & 5 & 3 & 4 & 4 & 2 & 5 & 1 & 2 & 5 & 4 \\
\hline $\begin{array}{l}\text { 5) Is it clear } \\
\text { when the } \\
\text { information } \\
\text { used or } \\
\text { reported in } \\
\text { the } \\
\text { publication } \\
\text { was } \\
\text { produced? }\end{array}$ & 4 & 5 & 5 & 1 & 5 & 5 & 2 & 5 & 1 & 2 & 5 & 5 \\
\hline $\begin{array}{l}\text { 6. Is it } \\
\text { balanced } \\
\text { and } \\
\text { unbiased? }\end{array}$ & 4 & 5 & 5 & 3 & 3 & 5 & 1 & 5 & 1 & 2 & 5 & 5 \\
\hline $\begin{array}{l}\text { 7. Does it } \\
\text { provide } \\
\text { details of } \\
\text { additional } \\
\text { sources of } \\
\text { support and } \\
\text { information? }\end{array}$ & 4 & 5 & 5 & 3 & 1 & 5 & 1 & 5 & 2 & 2 & 5 & 5 \\
\hline $\begin{array}{l}\text { 8. Does it } \\
\text { refer to } \\
\text { areas of } \\
\text { uncertainty? }\end{array}$ & 5 & 1 & 5 & 3 & 1 & 3 & 1 & 5 & 2 & 3 & 5 & 4 \\
\hline $\begin{array}{l}\text { 9. Does it } \\
\text { describe } \\
\text { how each } \\
\text { treatment } \\
\text { works? }\end{array}$ & 4 & 5 & 5 & 1 & 1 & 4 & 1 & 5 & 2 & 2 & 5 & 4 \\
\hline $\begin{array}{l}10 . \text { Does it } \\
\text { describe the } \\
\text { benefits of } \\
\text { each } \\
\text { treatment? }\end{array}$ & 5 & 5 & 5 & 5 & 5 & 3 & 1 & 5 & 2 & 2 & 5 & 5 \\
\hline $\begin{array}{l}\text { 11. Does it } \\
\text { describe the } \\
\text { risks of each } \\
\text { treatment? }\end{array}$ & 5 & 5 & 5 & 3 & 2 & 4 & 1 & 5 & 2 & 2 & 5 & 5 \\
\hline $\begin{array}{l}\text { 12. Does it } \\
\text { describe } \\
\text { what would } \\
\text { happen if no } \\
\text { treatment is } \\
\text { used? }\end{array}$ & 1 & 5 & 1 & 5 & 2 & 4 & 1 & 5 & 2 & 2 & 5 & 4 \\
\hline $\begin{array}{l}\text { 13. Does it } \\
\text { describe } \\
\text { how the } \\
\text { treatment } \\
\text { choices } \\
\text { affect the } \\
\text { overall } \\
\text { quality of } \\
\text { life? }\end{array}$ & 4 & 1 & 5 & 1 & 1 & 2 & 1 & 5 & 2 & 2 & 5 & 5 \\
\hline
\end{tabular}




\begin{tabular}{|c|c|c|c|c|c|c|c|c|c|c|c|c|}
\hline $\begin{array}{l}\text { Name of the } \\
\text { country }\end{array}$ & $\begin{array}{l}\text { Republic } \\
\text { of } \\
\text { South } \\
\text { Korea }\end{array}$ & Argentina & Canada & Nigeria & $\begin{array}{l}\text { South } \\
\text { Africa }\end{array}$ & Australia & India & Indonesia & Bangladesh & Kazakhstan & $\begin{array}{l}\text { Czech } \\
\text { Republic }\end{array}$ & $\begin{array}{l}\text { United } \\
\text { Arab } \\
\text { Emirat }\end{array}$ \\
\hline $\begin{array}{l}\text { 14. Is it clear } \\
\text { that there } \\
\text { may be } \\
\text { more than } \\
\text { one possible } \\
\text { treatment } \\
\text { choice? }\end{array}$ & 4 & 5 & 5 & 1 & 5 & 5 & 5 & 5 & 1 & 2 & 5 & 5 \\
\hline $\begin{array}{l}15 . \text { Does it } \\
\text { provide } \\
\text { support for } \\
\text { shared } \\
\text { decision- } \\
\text { making? }\end{array}$ & 4 & 1 & 5 & 3 & 1 & 4 & 3 & 5 & 3 & 2 & 5 & 5 \\
\hline $\begin{array}{l}\text { 16. Based } \\
\text { on the } \\
\text { answers to } \\
\text { all of the } \\
\text { above } \\
\text { questions, } \\
\text { rate the } \\
\text { overall } \\
\text { quality of } \\
\text { the } \\
\text { publication } \\
\text { as a source } \\
\text { of } \\
\text { information } \\
\text { about } \\
\text { treatment } \\
\text { choices: }\end{array}$ & 5 & 4 & 4 & 3 & 2 & 4 & 2 & 5 & 2 & 3 & 5 & 4 \\
\hline
\end{tabular}

\section{Declarations}

\section{Competing interests}

The authors declare no competing interests.

\section{Figures}

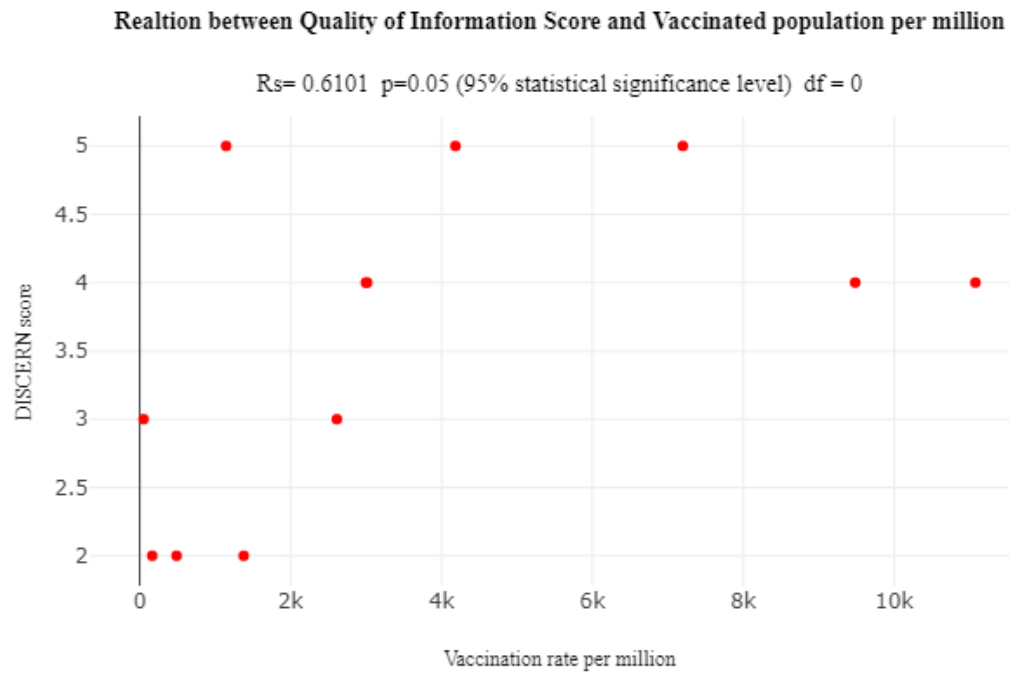

Figure 1

Scatter plot for correlation between Vaccination rate and DISCERN score 
Realtion between Quality of Information Score and Vaccinated population per million

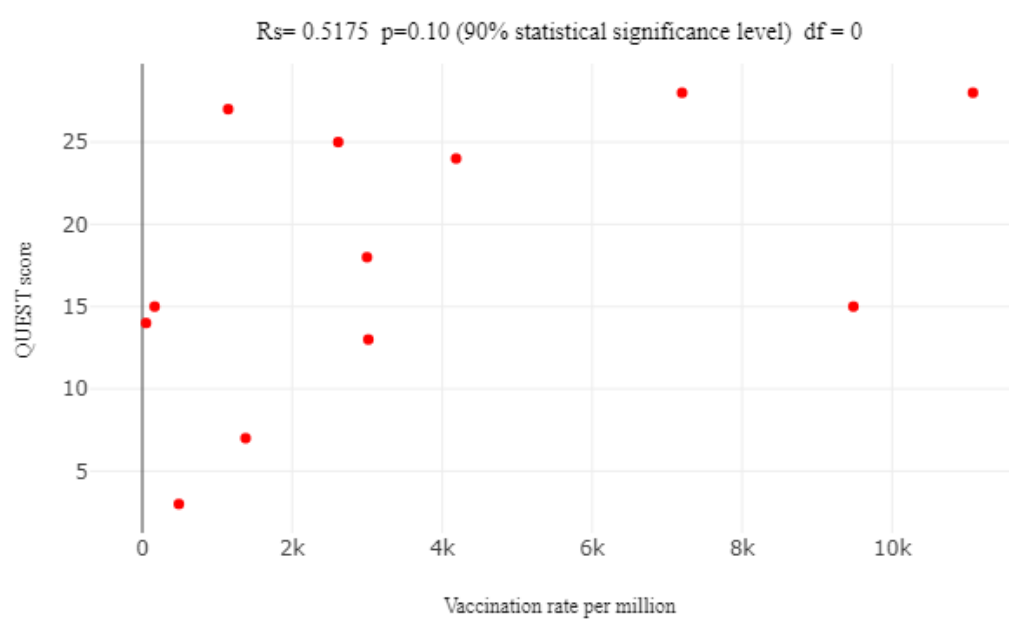

Figure 2

Scatter plot for correlation between Vaccination rate and QUEST score

\section{Supplementary Files}

This is a list of supplementary files associated with this preprint. Click to download.

- Supplimentaryfile.pdf 